\title{
Patient navigators becoming the norm in Canada
}

$\mathrm{C}$ onfused, disoriented and lost. Directions are readily available to navigate city roads but what about the road to cancer recovery? Where's the map to direct patients through the twists, turns and unmarked pathways of the health care system?

Increasingly, the North American solution isn't a map but rather a personal guide known as a patient navigator. But unlike the United States, where patient navigation is a somewhat helter-skelter unregulated occupation, (www.cmaj.ca /lookup/doi/10.1503/cmaj.109-3973), in Canada, it's slightly more regulated, with often-defined roles and responsibilities.

That responsibility typically involves connecting patients who have cancer with the right doctors and ensuring that they have access to the host of available therapies and resources. Navigators are also there to ensure continuity of care and to get answers to questions patients have about their diagnosis.

Although the profession is still somewhat embryonic in nature, navigators have been appointed in virtually all provinces, with Nova Scotia leading the way. They are largely the product of patient demand, says Sandra Cook, patient navigation project manager for Cancer Care Nova Scotia. The "overwhelming recommendation coming from the patients, the survivors and their families was that the system was extremely complex and they needed assistance in just transitioning through the maze."

Health care reforms in the 1990s, and the shift toward ambulatory care, limited the time a physician could spend with a patient and reduced the ability of a physician to offer information about the impact of a diagnosis and available treatment options, Cook adds. "In a half hour to hour appointment, if you don't get it, who do you turn to because the next patients are waiting."

Cook asserts that a minimum of 13 (and a mean of 32) physicians are involved with patients who progress beyond stage one cancer. "When you think of the communication challenges

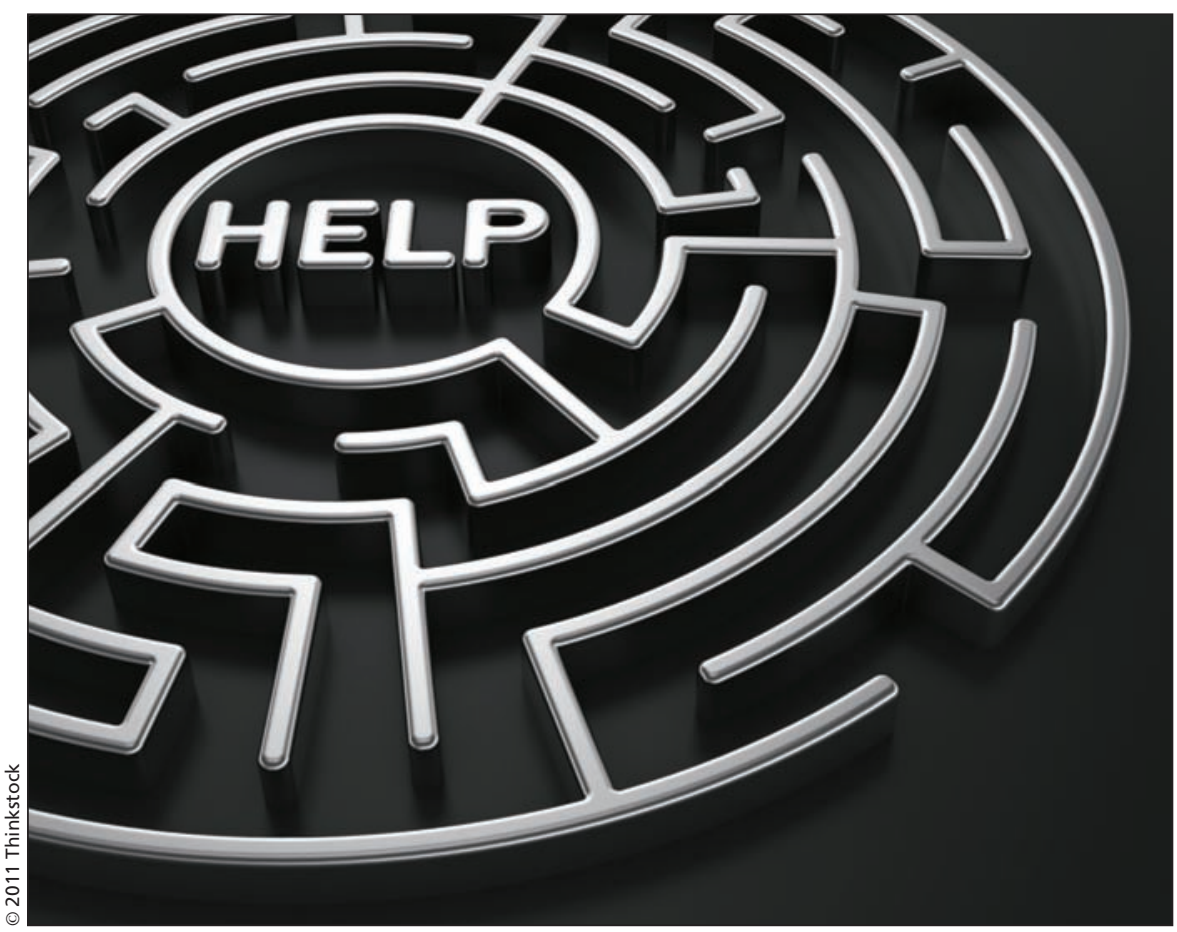

Patient navigators guide people through the health care maze, connecting them with the right doctors and helping them gain access to available therapies.

with that, having someone who knows each of the phases that you're transitioning through helps," she adds.

Navigators provide a measure of familiarity and security for patients, she adds. "Patients have described the experience as being on a conveyer belt, it stops, you fall off and then you crawl on to the next phase but there doesn't seem to be a connection so they use the navigator as that bridge so they don't have that sense of falling off the conveyer belt quite as quick but it's continuous."

In addition to connecting patients to resources and specialists, navigators also help patients obtain financial resources to cover such costs as transportation to a cancer centre and chemotherapy.

Even with universal health care, patients can't "walk away from the issue of finance," says Margaret Fitch, head of oncology nursing and co-director of the patient and family support program at the Odette Cancer Centre in Sunnybrook Health Sciences Centre in Toronto, Ontario.
Treatment may also require time off work, which contributes to financial pressure, adds Fitch, who got involved with patient navigation after chairing a federally funded Canadian Partnership Against Cancer action group in 2007.

"When I first started looking at all this, it just felt like a dog's breakfast. There were so many different notions, so many different ideas," she says.

Unlike the US, where community and private models of patient navigation have flourished, Canada has adopted a more regulatory approach to the profession, although programs do vary from province to province.

Most Canadian navigators are nurses. In Nova Scotia, a navigator must be certified in oncology and have at least five years' experience working with patients who have cancer. Oncology certification is also a requirement in Quebec which has about 270 l'infirmière pivot en oncology. An Ontario navigation program is still in its project phase so there are no fixed certification 
requirements in the province, although navigators must have some nursing experience in oncology.

In contrast to other provinces, Ontario has focused on integrating a navigator as early as possible in the process of providing treatment for cancer, even before official diagnosis, Fitch says.

"In our reviews and work with patients, what they have told us and what primary care providers have told us is that the worst wait is from time of suspicion to getting into the system and that's why we've placed the navigators in the diagnostic phase of care," adds Esther Green, provincial head, nursing and psychosocial oncology at Cancer Care Ontario.

If cancer is suspected, a navigator speaks with the patient over the phone about initial and possible follow-up tests that will be undertaken.

The province currently is running a pilot of involving 14 provincially funded navigators, although some cancer programs have found funding for navigators outside of government.

Some jurisdictions also appear to be evolving toward the creation of culturally sensitive navigators. Typically, those have taken the form of "peers" — community representatives, and even cancer survivors, who fill the language needs and can help address cultural gaps. The Odette centre, for example, implemented a peer navigator program for Toronto's Chinese population, designating five navigators who are able to speak to patients in either Cantonese or Mandarin.

Similar peer programs are also being developed in Asian communities in British Columbia, as well as in Aboriginal communities across the countries. "We have language issues in many areas of the country," says Cook. "Certainly our First Nation communities have huge issues."

Newfoundland and Labrador appears to be adopting a similar approach for rural areas. Two nurses have trained over 50 peer navigators stationed in different communities.

But while they help link patients to treatment and information, there are lim- its on their responsibility because they aren't licensed professionals, Fitch says. "In some ways we're beginning to see the building of some of the different types of programs, focused on different intervals of the cancer journey, but what we're trying to do from a national point of view is making sure we have consistent role descriptions, consistent ideas about what the competencies are to actually hold these roles."

Cook says Nova Scotia is currently examining whether navigators should be more involved in providing palliative relief, which might lead to fewer emergency department visits.

There's also a need to sort out the degree to which navigators are involved with cancer survivors, particularly as good nutrition, active living and regular screening help to reduce cancer recurrence, she adds. "We're trying to be proactive. Often times the health care system is reactive." - Erin Walkinshaw, Ottawa, Ont.

CMAJ 2011. DOI:10.1503/cmaj.109-3974 